\title{
Samson-Veröffentlichungen ab 1972
}

\section{Schriften}

1. Urheberrecht, ein kommentierendes Lehrbuch, 1973, Verlag Dokumentation München, UTB 24

(War in der Bibliographie 1972 schon angekündigt).

\section{Aufsätze}

2. Die urheberrechtliche Regelung in Dienst- und Tarifverträgen in: UFITA Bd. 64 (1972) S. 181, Festschrift für Georg Roeber.

3. Die Entstellung urheberrechtlich geschützter Werke und Leistungen in: Festschrift für den Verleger Ludwig Strecker.

Verlag B. Schott's Söhne, Mainz, 1973, S. 372.

4. La nouvelle réglementation du droit de suite en République Fédérale d'Allemagne in: Revue Internationale du Droit d'Auteur (RIDA), Juli 1973 S. 39.

5. Der neue Schulbuchparagraph in: Blickpunkt Schulbuch 1973 , Heft 15 S. 23.

6. Anspruch auf die Schulbuchvergütung hat nur der Urheber in: UFITA Bd. 71 (1974) S. 65.

7. Die Computerkunst und das Urheberrecht in: UFITA Bd. 72 (1975) S. 89.

8. Die Topik im Gewerblichen Rechtsschutz und Urheberrecht. UFITA Bd. 74 (1975) S. 127 - Festschrift für Wilhelm Herschel.

9. Urhebervertragsgesetz oder Verzicht auf eine gesetzliche Regelung in: FILM UND RECHT Nr. 5/1973 S. 299.

10. Urheberrecht oder Leistungsschutzrecht des Bühnenregisseurs in: GRUR 1976, 191.

11. Bemerkungen zur Arbeitssitzung beim Institut für Film- und Fernsehrecht am 28. Juni 1976 in: FILM UND RECHT Nr. 7/1976 S. 460 (Datenverarbeitungs-System JURIS).

12. Anmerkung zum Bremer OLG-Urteil vom 14. Juli 1976 (Fotokopie) in: FILM UND RECHT Nr. 9/1976 S. 611.

13. Urheberrecht und Regie. Orientierungshilfe für die Arbeitssitzung beim Institut für Film- und Fernsehrecht am 5. November 1976, in: FILM UND RECHT Nr. 10/1976 S. 686. 


\section{Besprechungen}

Weitere Buchbesprechungen $u$. a. betr.

Palandt, BGB - Kommentar, 33. und 34. Aufl., in: UFITA Bd. 75 (1976) S. 353.

Mario M. Pedrazzini, Kunst und Recht in: UFITA Bd. 77 (1976) S. 372. Ferdinand Wassner, Kunst, Geschmack und unlauterer Wettbewerb in: UFITA Bd. 75 (1976) S. 373.

Model und Creifelds, Staatsbürger-Taschenbuch, 14. Aufl., in: UFITA Bd. 75 (1976) S. 384.

Erman, BGB - Kommentar, 6. Aufl., in UFITA Bd. 78 (1977) S. 375. 
Teil I 
